\title{
CLASSIFICATION RULE FOR DETERMINING THE TEMPERATURE REGIME OF INDUCTION GRAY CAST IRON
}

\author{
Iraida Stanovska \\ Department of Higher Mathematics and Modeling Systems ${ }^{1}$ \\ stanovskairaida@gmail.com \\ Vasyl Duhanets \\ Department of Technical Service and General Technical Disciplines \\ State Agrarian and Technical University in Podilia \\ 13 Shevchenko str., Kamianets-Podilskyi, Ukraine, 32300 \\ duganec-vasil@gmail.com \\ Lada Prokopovych \\ Department of Cultural Studies, Art and Culture Philosophy Studies ${ }^{l}$ \\ lada.prokopovich@gmail.com \\ Serhiy Yakhin \\ Department of Industrial Engineering \\ Poltava State Agrarian Academy \\ 1/3 Skovorody str., Poltava, Ukraine, 36003 \\ sergii.iakhin@pdaa.edu.ua \\ ${ }^{1}$ Odessa National Polytechnic University \\ 1 Shevchenko ave., Odessa, Ukraine, 65044
}

\begin{abstract}
The complexity of using instruments for measuring the technological parameters of induction melting in a continuous mode, and sometimes the impossibility of this, requires the creation of reliable indirect methods for assessing the numerical values of these parameters. This is especially important for quality control of control systems that ensure a given melting temperature regime. The paper proposes a classification rule based on parametric classification methods, which makes it possible to determine the temperature regime of induction melting based on the $\mathrm{SiO}_{2}$ content in the slag and the distribution coefficient $K_{d}=\mathrm{SiO}_{2} /(\mathrm{FeO}+\mathrm{MnO})$.

Checking the classifying ability of the obtained rule showed that it is high, since for all the numerical data of the factor-signs, both the high-temperature and low-temperature modes were classified correctly. The restrictions on the application of the classification rule are shown, among them: the restrictions imposed by the range of variation of the values of the attribute factors, and the restrictions imposed by the small sample of the initial data, as well as the arbitrary area of their distribution in the space of the factor-attributes.

The rule is presented in a normalized form, and also converted to natural form for ease of practical use.

Application of the rule can be recommended to technologists of metallurgical production of foundries to check the compliance of the technological process operations with the specified melting regulations. It can also be used to diagnose processes or temperature control systems that determine the quality of the resulting cast iron. To do this, it is enough to substitute the actual values of $\mathrm{SiO}_{2}$, and $K_{d}$ into the classification rule. The value of the distribution coefficient $K_{d}$ is calculated according to the actual data on the content of $\mathrm{FeO}$ and $\mathrm{MnO}$ in the slag.

Keywords: induction melting, high-temperature regime, low-temperature regime, slag, temperature control, factor-signs, classifying rule.
\end{abstract}

DOI: $10.21303 / 2461-4262.2021 .001604$

\section{Introduction}

Advances in the production of castings from high-quality cast iron, including synthetic cast iron, arouse increased interest in this structural material as promising for highly loaded parts of diesel internal combustion engines (ICE). Cast iron melting technologies are considered as an important part of the design and technological preparation for the production of internal combustion engine parts, primarily pistons, which of all engine parts operate in the most difficult conditions and determine the reliability and service life of the engine as a whole [1]. The improvement of such 
technological processes is aimed at obtaining a high-quality alloy with improved mechanical characteristics, for which the cast iron melt is subjected to combined modification using the minimum amount of alloying elements [2-4]. The alloying elements used, among which Cr, Ni prevail, as well as the transition to the field of special, for example, aluminum cast irons, for the production of cast parts for internal combustion engines, allow not only to solve the problem of improving the mechanical characteristics, but also to reduce the weight and size characteristics of the parts. However, the use of combined modification and alloying technologies requires the selection of rational technological modes of melting and the maintenance of such modes throughout the entire campaign. In modern furnaces, these possibilities are often laid down at the design level. Thus, in [5] it was noted that single-circuit circulation with a downward flow of metal is expedient when alloying the metal and introducing microadditives, as well as when doping the melt with intermetallic compounds and nanopowders. This is facilitated by the concentration of power in the upper part of the crucible, which causes intense heating and turbulence of metal flows in the sub-slag layer. As a result of these processes, it becomes possible to quickly introduce and distribute alloying materials and creates favorable conditions for adjusting the chemical composition and homogenization of the bath [5].

From a structural point of view, the possibility of controlling induction furnaces is realized on the basis of methods for controlling current inverters [6]. At the same time, the author gives a number of arguments in favor of the need for a certain clarification of the term «current inverter» associated with the development of the element base of power conversion equipment. In particular, in work [6] it is noted that frequency converters for installations of induction heating and melting of metals are performed mainly in the form of systems with a pronounced direct current link, containing a singleor multiphase controlled (or uncontrolled) rectifier, a direct current link and an autonomous inverter of a given class. The DC link can include, separately or in various combinations, a filter, an active or passive clamp, a DC controller and other units made according to the corresponding schemes. Traditionally, in induction installations of medium (from hundreds of kilowatts to units of megawatts) and large (tens of megawatts) power, single-phase bridge current inverters are widely used.

The implementation on induction furnaces, within the framework of design solutions, of technological capabilities for controlling the thermal regime of melting and the dynamics of the movement of the melt stimulates the flow of oxidation-reduction processes in the bath, which provide the specified chemical composition of the alloy at the output. Thus, in works [7, 8], studies are described that are devoted to identifying the regularities of carbon transformations at high temperatures, which are characteristic of smelting ferrous alloys in induction furnaces, as the main processes to be controlled by smelting technologies. In particular, it is said that as a result of studying the process of carbon oxidation for three different brands in an environment of carbon dioxide at different temperatures, thermogravimetric analysis data were obtained, on the basis of which the equations of the process rate were determined. The resulting kinetic equations, the parameters of which are the pre-exponential factor and the activation energy of the heterogeneous reaction of carbon oxidation in a carbon dioxide medium, can be used among mathematical models in problems of melting control. A similar approach was used in [9], where the calculation of the aforementioned parameters of the kinetic equations was performed for melts doped with vanadium. It should be noted that the regulation of the thermal regime of induction melting should take into account the factor of using modifiers and a complex of alloying elements, if they are introduced in minimum quantities. This is due to the need to ensure a given value of alloy overheating as one of the essential factors for regulating the formation of microstructure [10-12], which determines the mechanical or special properties of cast iron.

The above arguments allow to speak about the importance of control and regulation of induction melting processes, in particular, using computer-integrated solutions in terms of automating these processes. Deviations from the specified melting temperature conditions caused by a malfunction of the automation system can lead to deviations in the chemical composition, microstructure and properties of cast iron. Therefore, criteria for evaluating the performance indicators of the automation equipment included in the temperature control loops are needed, which make it possible to determine the deviations from the specified melting temperature regime. A quantitative measure of such an assessment may indicate a violation of the normal functioning of the temperature control loops as a subsystem of the induction melting automation system. 


\section{Materials and methods of research}

The study is based on the concept proposed in [13] that the composition of the slag can be used to determine the deviation of the melting temperature from normal. The schematic diagram of temperature control is shown in Fig. 1 [14].

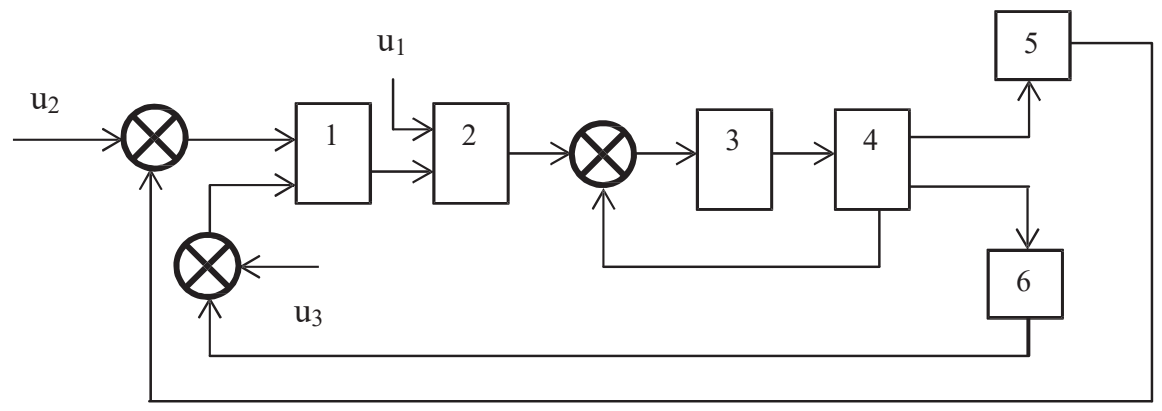

Fig. 1. Scheme for regulating the temperature regime of induction melting:

1 - thermal regime controller, 2 - setpoint setting unit for electric mode controller,

3 - electric mode controller, 4 - temperature measuring device, 5 - metal temperature sensor,

6 - lining temperature sensor, $u_{1}$ - setting the directive schedule of the electric melting mode, $u_{2}$ - setting the directive schedule of the melting temperature regime, $u_{3}-$ setting the maximum permissible lining temperature

The temperature correction mode is based on periodic monitoring of the metal temperature and continuous monitoring of the lining temperature. The thermal mode controller 1 is connected with the metal temperature sensors 5 and the lining temperature 6 and acts on the unit for setting the setpoint of the electric mode controller 2. Before melting, in 2 and 1, directive graphs of the electric $\left(u_{1}\right)$ and temperature $\left(u_{2}\right)$ melting modes, as well as the measurement program are introduced metal temperatures (in time or in connection with technological operations) and the maximum permissible lining temperatures $\left(u_{3}\right)$.

According to the signal of the difference between the actual and the set metal temperature, the computing unit 2 calculates the parameters of the electric mode, which are automatically set and maintained by the controller of the electric mode 3 . When the critical temperatures of the furnace lining are reached, unit 2 reduces the power supplied to the furnace. The temperature is measured by the device 4 .

For the study, let's use data on the content of $\mathrm{SiO}_{2}(\%), \mathrm{FeO}(\%), \mathrm{MnO}(\%)$ in slags from [13]. After processing the data to check the limits of applicability of the classifying rule, the results of [15] were used, while the data were extrapolated to the low-temperature region and equations (1)-(3) were used:

$$
\begin{gathered}
\mathrm{SiO}_{2}=25.302 e^{0.0008 T}, \\
\mathrm{FeO}=-83.49 \ln T+613.87, \\
\mathrm{MnO}=-19.42 \ln T+143.96,
\end{gathered}
$$

where $T$ - melt temperature.

Equations (1)-(3) were derived from Excel's built-in trend tool.

As a research method, the parametric method of classification was used, which has proven itself in the problems of predicting the quality of castings and materials for them [16, 17], as well as diagnostics of technological processes in metallurgical production [18, 19].

The discriminant function in this case has the form of a classifying rule:

$$
y=f(x)=x^{T} \operatorname{cov}^{-1}(x)\left(m_{1}-m_{2}\right),
$$


where $y=f(x)$ - value of the discriminant function, depending on the location of the classifying point in the space of the factor-signs $x^{T}, \operatorname{cov}^{-1}(x)$ - inverse matrix of the covariance, $m_{1}, m_{2}$ - mathematical expectations of the values of the factor-signs for classes 1 and 2, respectively, calculated by formulas (5), (6) accordingly, $T$ denotes the transposition operation.

$$
\begin{aligned}
& m_{1}=\frac{1}{N_{1}}\left(\sum_{j=1}^{N_{1}} x_{1 j} \sum_{j=1}^{N_{1}} x_{2 j}\right)^{T}, \\
& m_{2}=\frac{1}{N_{2}}\left(\sum_{j=1}^{N_{2}} x_{1 j} \sum_{j=1}^{N_{2}} x_{2 j}\right)^{T} .
\end{aligned}
$$

In formulas (5), (6), the values $N_{1}$ and $N_{2}$ denote the number of elements in classes 1 and 2, respectively.

Class covariance matrices were calculated using the formula:

$$
\operatorname{cov}(x)=\frac{1}{N_{i}} \sum_{j=1}^{N_{i}} X_{i} X_{j}^{T}-m_{i} m_{i}^{T} .
$$

The classifying rule, which allows to check whether the melting was carried out at high-temperature mode or at low-temperature mode, in general form corresponds to equation (8):

$$
x^{T} \operatorname{cov}^{-1}(x)\left(m_{1}-m_{2}\right)=\frac{1}{2}\left(m_{1}+m_{2}\right)^{T} \operatorname{cov}^{-1}(x)\left(m_{1}-m_{2}\right) \text {. }
$$

The complete algorithm for calculating the parameters of the classifying rule is given in [13],

\begin{tabular}{|c|c|c|c|c|c|c|c|c|}
\hline \multirow{3}{*}{$\begin{array}{l}\text { Sample } \\
\text { number }\end{array}$} & \multicolumn{8}{|c|}{ Slag composition, $\%$} \\
\hline & \multicolumn{4}{|c|}{ High temperature mode } & \multicolumn{4}{|c|}{ Low temperature mode } \\
\hline & $\mathrm{SiO}_{2}$ & $\mathrm{FeO}+\mathrm{Fe}_{2} \mathrm{O}_{3}$ & MnO & $K_{d}$ & $\mathrm{SiO}_{2}$ & $\mathrm{FeO}+\mathrm{Fe}_{2} \mathrm{O}_{3}$ & MnO & $K_{d}$ \\
\hline 1 & 56.62 & 20.78 & 1.19 & 0.93 & 39.32 & 40.77 & 1.31 & 2.58 \\
\hline 2 & 65.38 & 16.82 & 0.93 & 1.11 & 44.55 & 35.92 & 2.27 & 3.68 \\
\hline 3 & 76.18 & 7.14 & 2.48 & 1.45 & 47.16 & 31.18 & 1.2 & 8.09 \\
\hline 4 & 70.85 & 10.12 & 1.22 & 1.67 & 50.17 & 29.4 & 0.75 & 6.25 \\
\hline 5 & 69.95 & 9.86 & 0.41 & 2.26 & 53.22 & 23.55 & 1.15 & 6.79 \\
\hline
\end{tabular}
Table 1 shows the initial data for constructing a classifying rule.

Table 1

Experimental industrial data

$\mathrm{SiO}_{2}$ and distribution coefficient $K_{d}=\mathrm{SiO}_{2} /(\mathrm{FeO}+\mathrm{MnO})$ were chosen as the factors. All calculations were carried out in a normalized form, in which the values of the factor-signs, denoted by $x_{1}$ and $x_{2}$, were in the range $[-1 ;+1]$. The following actual values of the attribute factors corresponded to this normalized range: $\mathrm{SiO}_{2}(\%)=[65.38 ; 76.18], K_{d}=[0.93 ; 2.26]-$ for the high-temperature regime, $\mathrm{SiO}_{2}(\%)=[39.32 ; 53.22], K_{s}=[2.58 ; 8.09]$ - for low-temperature mode. That is, the general normalized range was as follows: $\mathrm{SiO}_{2}(\%)=[39.32 ; 76.18], K_{S}=[0.93 ; 8.09]$.

The classification rule based on equation (8) had a general form:

$$
\begin{aligned}
& x^{(j)} \in \text { Class \#1 if } y \geq y_{0}, \\
& x^{(j)} \in \text { Class } \# 2 \text { if } y<y_{0} .
\end{aligned}
$$




\section{Results and discussion of research results}

A classification rule is obtained, presented in a standardized form:

$$
\begin{aligned}
& x^{j} \in \text { class } \# 1 \text { if }-21.8531 x_{1}+31.377 x_{2} \geq-12.0605, \\
& x^{j} \in \text { class } \# 2 \text { if }-21.8531 x_{1}+31.377 x_{2}<-12.0605 .
\end{aligned}
$$

The left side of the inequality is from equation (4), and the distribution of this value for the selected values of the attribute factors is shown in Fig. 2.

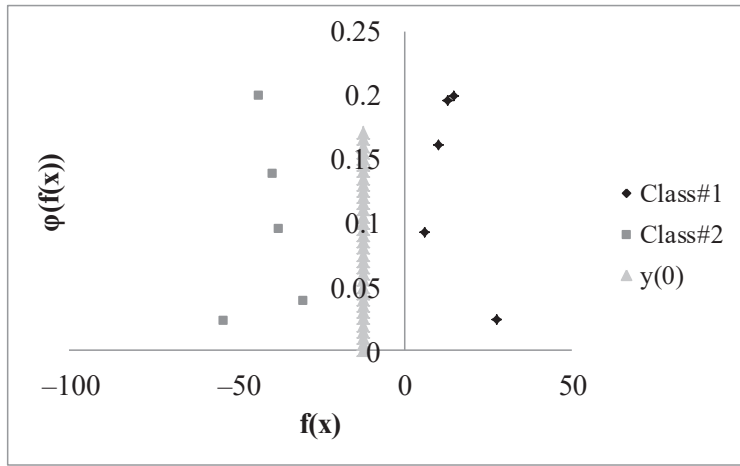

Fig. 2. Distribution of value $y=f(x)$

From Fig. 2, it can be seen that all experimental points are correctly distributed among classes. Therefore, the obtained rule (10) can be used to establish the melting temperature. For practical application, it is necessary to transform it to its natural form, using the ranges of variation of the values of the factor-signs selected in the normalization process. The final rule is received:

$$
\begin{aligned}
& x^{j} \in \text { class } \# 1 \text { if }-21.8531\left(\frac{x_{1}-57.75}{18.43}\right)+31.377\left(\frac{x_{2}-4.51}{3.58}\right) \geq-12.0605, \\
& x^{j} \in \text { class } \# 2 \text { if }-21,8531\left(\frac{x_{1}-57.75}{18.43}\right)+31.377\left(\frac{x_{2}-4.51}{3.58}\right)<-12.0605 .
\end{aligned}
$$

The results of checking the limits of applicability of the rule are given in Table 2. They were obtained by substituting in (11) the numerical values of the attribute factors from work [15], having previously used equations (1)-(3).

Table 2

Verification results of the classification rule

\begin{tabular}{cccccc}
\hline $\boldsymbol{T}^{\circ} \mathbf{C}$ & $\mathbf{S i O}_{\mathbf{2}}$ & FeO & MnO & $\boldsymbol{K}_{\boldsymbol{d}}$ & $\boldsymbol{y}=\boldsymbol{f}(\boldsymbol{x})$ \\
\hline \multicolumn{7}{c}{ High temperature mode } \\
\hline 1500 & 84.01 & 3.31 & 1.94 & 16 & $\mathbf{7 0 . 3 9 7 2 2}$ \\
1475 & 82.34 & 4.71 & 2.26 & 11.81 & $\mathbf{3 5 . 4 6 0 5}$ \\
1450 & 80.71 & 6.14 & 2.6 & 9.23 & $\mathbf{1 4 . 8 8 6 8 5}$ \\
1425 & 79.11 & 7.59 & 2.93 & 7.52 & $\mathbf{1 . 6 3 8 8 9}$ \\
1400 & 77.55 & 9.07 & 3.28 & $\mathbf{- 7 . 3 7 7 5 2}$ \\
\hline & & Low temperature mode & & \\
\hline 1300 & 71.58 & 15.26 & 4.72 & 3.58 & $\mathbf{- 2 4 . 1 1 4 4}$ \\
1275 & 70.17 & 16.88 & 5.09 & 3.19 & $\mathbf{- 2 5 . 8 9 7 4}$ \\
1250 & 68.78 & 18.53 & 5.48 & 2.86 & $\mathbf{- 2 7 . 1 7 3 4}$ \\
1225 & 67.42 & 20.22 & 5.87 & 2.58 & $\mathbf{- 2 8 . 0 5 6 8}$ \\
1200 & 66.08 & 21.94 & 6.27 & 2.34 & $\mathbf{- 2 8 . 6 3 1 4}$
\end{tabular}


From Table 2 it is possible to see that for both modes, rule (11) shows opposite results in relation to the determination of the temperature regime. The reason for this is that the values of the factor-signs obtained from the results of approximation and extrapolation of the results of work [15] are far beyond the variation intervals adopted in this study: $\mathrm{SiO}_{2}(\%)=[66.08 ; 84.01]$, $K_{d}=[2.34 ; 16]$ (Table 2) in comparison with $\mathrm{SiO}_{2}(\%)=[39.32 ; 76.18], K_{d}=[0.93 ; 8.09]$ (Table 1).

Therefore, before applying rule (11), it is necessary to check whether the actual data on $\mathrm{SiO}_{2}$ and $K_{d}$ belong to the $\mathrm{SiO}_{2}$ range $(\%)=[39.32 ; 76.18], K_{d}=[0.93 ; 8.09]$. This is a limitation on the application of the resulting classification rule. Another limitation of this study is that the rule is derived from a small sample of experimental data. An increase in the sample size and optimization of the experimental data area, for example, based on artificial orthogonalization [20], would allow obtaining a more accurate result.

Therefore, the direction of further research is the collection of primary data to increase the sample size and the formation of such an area of the space of factor-signs that will allow the most accurate calculation of the parameters of the classifying rule. Expanding the range of variation in this case will make it possible to obtain classification rules for wider areas of the space of factor-signs.

\section{Conclusions}

The resulting classification rule allows one to determine the temperature regime of induction melting based on the $\mathrm{SiO}_{2}$ content in the slag and the distribution coefficient $K_{d}=\mathrm{SiO}_{2} /(\mathrm{FeO}+\mathrm{MnO})$. Checking its classifying ability shows that it is high, since for all numerical data of factor-signs, all modes are classified correctly.

\section{References}

[1] Puliaiev, A., Orendarchuk, J., Penziev, P., Akimov, O., Marynenko, D., Marchenko, A. (2017). Development of a system for organizing a modular design and technological preparation for the production of cast iron pistons for internal combustion engines. Technology Audit and Production Reserves, 3 (1 (35)), 23-27. doi: https://doi.org/10.15587/2312-8372.2017.105636

[2] Akimov, O. V., Marchenko, A. P. (2008). Eksperimental'nye issledovaniya i komp'yuternoe modelirovanie materialov dlya blok-kartera DVS. Eastern-European Journal of Enterprise Technologies, 5 (1 (35)), 52-57.

[3] Demin, D. A., Pelikh, V. F., Ponomarenko, O. I. (1998). Complex alloying of grey cast iron. Litejnoe Proizvodstvo, 10, $18-19$.

[4] Demin, D. A., Pelikh, V. F., Ponomarenko, O. I. (1995). Optimization of the method of adjustment of chemical composition of flake graphite iron. Litejnoe Proizvodstvo, 7-8, 42-43.

[5] Trauzel', D., Shlyukaber, Donbah, F. (2003). Realizatsiya spetsial'nyh tehnologicheskih i metallurgicheskih zadach v induktsionnyh pechah sredney chastoty. Liteyshchik Rossii, 5, 20-23.

[6] Silkin, E. (2007). Realizatsiya i sposoby upravleniya ventilyami v invertorah toka preobrazovateley chastoty dlya ustanovok induktsionnogo nagreva i plavki metallov. Silovaya elektronika, 3, 108-114.

[7] Roberts, D. G., Hodge, E. M., Harris, D. J., Stubington, J. F. (2010). Kinetics of Char Gasification with CO2 under Regime II Conditions: Effects of Temperature, Reactant, and Total Pressure. Energy \& Fuels, 24 (10), 5300-5308. doi: https://doi.org/ 10.1021/ef100980h

[8] Kim, S. K., Park, C. Y., Park, J. Y., Lee, S., Rhu, J. H., Han, M. H. et. al. (2014). The kinetic study of catalytic low-rank coal gasification under CO2 atmosphere using MVRM. Journal of Industrial and Engineering Chemistry, 20 (1), 356-361. doi: https:// doi.org/10.1016/j.jiec.2013.03.027

[9] Demin, D. A. (1998). Change in cast iron's chemical composition in inoculation with a Si-V-Mn master alloy. Litejnoe Proizvodstvo, 6, 35 .

[10] Endo, M., Yanase, K. (2014). Effects of small defects, matrix structures and loading conditions on the fatigue strength of ductile cast irons. Theoretical and Applied Fracture Mechanics, 69, 34-43. doi: https://doi.org/10.1016/j.tafmec.2013.12.005

[11] Fourlakidis, V., Diószegi, A. (2014). A generic model to predict the ultimate tensile strength in pearlitic lamellar graphite iron. Materials Science and Engineering: A, 618, 161-167. doi: https://oi.org/10.1016/j.msea.2014.08.061

[12] Cheng, Y., Huang, F., Li, W., Liu, R., Li, G., Wei, J. (2016). Test research on the effects of mechanochemically activated iron tailings on the compressive strength of concrete. Construction and Building Materials, 118, 164-170. doi: https://doi.org/ 10.1016/j.conbuildmat.2016.05.020

[13] Demin, D. (2020). Constructing the parametric failure function of the temperature control system of induction crucible furnaces. EUREKA: Physics and Engineering, 6, 19-32. doi: https://doi.org/10.21303/2461-4262.2020.001489 
[14] Shumihin, V. S., Kutuzov, V. P., Hramchenkov, A. I. et. al.; Aleksandrov, N. N. (Ed.) (1982). Vysokokachestvennye chuguny dlya otlivok. Moscow: Mashinostroenie, 222.

[15] Zavertkin, A. S. (2013). The influence of the lining's manufacturing technology and of cast iron's melting in induction furnaces on the slag forming. Novye Ogneupory (New Refractories), 1, 36-39.

[16] Ponomarenko, O., Trenev, N. (2013). Computer modeling of crystallization processes as a reserve of improving the quality of pistons of ICE. Technology Audit and Production Reserves, 6 (2 (14)), 36-40. doi: https://doi.org/10.15587/2312-8372.2013.19529

[17] Vasenko, Y. (2012). Technology for improved wear iron. Technology Audit and Production Reserves, 1 (1 (3)), 17-21. doi: https:// doi.org/10.15587/2312-8372.2012.4870

[18] Aouati, M. (2018). Improving the accuracy of classifying rules for controlling the processes of deculfuration and dephosphorization of Fe-C melt. Technology Audit and Production Reserves, 2 (3 (46)), 10-18. doi: https://doi.org/10.15587/ 2312-8372.2019.169696

[19] Aouati, M. (2017). Parametric identification in the problem of determining the quality of dusulfusation and deposphoration processes of Fe-C alloy. Technology Audit and Production Reserves, 2 (1 (34)), 9-15. doi: https://doi.org/10.15587/ 2312-8372.2017.99130

[20] Demin, D. (2017). Synthesis of optimal control of technological processes based on a multialternative parametric description of the final state. Eastern-European Journal of Enterprise Technologies, 3 (4 (87)), 51-63. doi: https://doi.org/10.15587/ 1729-4061.2017.105294 